\title{
Photoluminescent Enhancement by Effect of Incorporation Nickel in ZnO Films Grown
}

\author{
Delfino R. Gutiérrez-Olvera, Tomás Díaz-Becerril, Godofredo García-Salgado, \\ Antonio Coyopol-Solís, Enrique Rosendo-Andrés, Reina Galeazzi-Isasmendi, Ramón Peña-Sierra, \\ Crisóforo Morales-Ruiz, Roman Romano-Trujillo, and Fabiola G. Nieto-Caballero
}

\begin{abstract}
Microstructured films of undoped zinc oxide $(\mathrm{ZnO})$ and $\mathrm{ZnO}$ doped with nickel ( $\mathrm{ZnO}: \mathrm{Ni}$ ) were grown by hot filament chemical vapor deposition (HFCVD) technique on $\mathrm{Si}$ (100) substrates at $500{ }^{\circ} \mathrm{C}$. Pellets of $\mathrm{ZnO}$ and $\mathrm{ZnO}$ : $\mathrm{NiO}$ as oxidant agenst were used. A shift to the right around 0.17 degree of the X-Ray Diffraction pattern of the $\mathrm{ZnO}$ :Ni film was observed with respect to undoped $\mathrm{ZnO}$ films. Morphologically by Scanning Electron Microscopy was noticed a Core-Shell type growth in $\mathrm{ZnO}$ undoped and a nanostructured type (Nano-wire) in $\mathrm{ZnO}$ doped with Ni. Photoluminescence measurements showed an increase in the intensity of the green emission band of $\mathrm{ZnO}$ : Ni. It was attributed to defects of oxygen vacancies $\left(V_{0}\right)$, zinc vacancies $\left(V_{Z n}\right)$, zinc interstitials $\left(\mathbf{Z n}_{\mathbf{i}}\right)$, oxygen interstitials $\left(\mathrm{O}_{\mathrm{i}}\right)$, and oxygen vacancies complex $\left(\mathrm{V}_{\mathrm{o}}\right.$ complex) in the structure of the film. The incorporation of $\mathrm{Ni}$ atoms in the $\mathrm{ZnO}$ structure stresses the crystal lattice, leaving behind a large number of surface defects that increase the emission of PL.
\end{abstract}

Key word - Core-Shell, HFCVD, Nano-wires, Sea urchin, $\mathrm{ZnO}, \mathrm{ZnO}$ :Ni.

\section{INTRODUCTION}

$\mathrm{ZnO}$ commonly crystallizes in a Wurtzite-type hexagonal structure at $300 \mathrm{~K}$. It has a direct bandgap $\left(\mathrm{E}_{\mathrm{g}}\right)$ of $3.3 \mathrm{eV}$ as bulk material. It is a semiconductor with an n-type conductivity at room temperature [1]. This is mainly attributed to a large number of defects as oxygen vacancies $\left(\mathrm{V}_{\mathrm{O}}\right)$ [2], zinc vacancies $\left(\mathrm{V}_{\mathrm{Zn}}\right)$ [3], zinc interstitials $\left(\mathrm{Zn}_{\mathrm{i}}\right)$ [4], and oxygen interstitials $\left(\mathrm{O}_{\mathrm{i}}\right)$ [5]. Several authors have reported a p-type conductivity obtained, only in laboratories,

\footnotetext{
Submitted on August 03, 2021

Published on August 31, 2021.

Delfino R. Gutiérrez-Olvera, Universidad Autónoma de Puebla, México.

(e-mail: delfino.rgo@gmail.com).

Tomás Díaz-Becerril, Universidad Autónoma de Puebla, México.

(e-mail: tomas.diaz.be@gmail.com).

Godofredo García-Salgado, Universidad Autónoma de Puebla, México.

(e-mail: godgarcia@ ${ }^{@}$ ahoo.com).

Antonio Coyopol-Solís, Universidad Autónoma de Puebla, México.

(e-mail: acoyopol@gmail.com).

Enrique Rosendo-Andrés, Universidad Autónoma de Puebla, México. (e-mail: enrique171204@gmail.com).

Reina Galeazzi-Isasmendi, Universidad Autónoma de Puebla, México.

(e-mail: ingquim25@gmail.com).

Ramón Peña-Sierra, Centro de Investigación de estudios Avanzados del IPN, México.

(e-mail: rpsierra ${ }^{@}$ cinvestav.mx).

Crisóforo Morales-Ruiz, Universidad Autónoma de Puebla, México.

(e-mail: crisomr@ ${ }^{@}$ yahoo.com.mx).

Roman Romano-Trujillo, Universidad Autónoma de Puebla, México.

(e-mail: roman.romano@@gmail.com).

Fabiola G. Nieto-Caballero, Universidad Autónoma de Puebla, México.

(e-mail: ruscaballero@yahoo.com.mx).
}

by doping $\mathrm{ZnO}$ with different elements of the periodic table and with different deposition techniques. For example, by pulse laser deposition (PLD), metalorganic molecular-bean epitaxy (MOMBE), radiofrequency magnetron sputtering (RF Magnetron Sputtering), and metalorganic chemical vapor deposition (MOCVD); $\mathrm{ZnO}$ was doped with Arsenic [6], Nitrogen [6], Phosphorus [7], and Nitrogen [7], respectively. However, these results have been difficult to replicate in order to achieve the desired homojunction. By another hand, different morphological growths have been reported, such as microwires [8], microribbons [9], microspheres [9], and even nanometric structures as nanoparticles [10], nanorods [11], and nanowires [12] of $\mathrm{ZnO}$ with the aim of manufacture different types of devices as gas sensors [13], light-emitting diodes [14] photodetectors [15], high electron mobility transistors (HEMT) [16], [17], field-effect transistors (FET) [18] and thin-film transistors (TFT) [19]. In this work, microsphere and sea urchin-type structures were found; the last structure is obtained when $\mathrm{ZnO}$ films are doped with Nickel. The obtaining process consists of the interactions of Ho with $\mathrm{ZnO}: \mathrm{NiO}$ pellets for the generation of gaseous precursors and their subsequent deposit on silicon substrate using the HFCVD technique. This with the aim of improving the photoluminescence of $\mathrm{ZnO}$ for a possible application as light-emitting devices.

\section{MATERIALS AND METHODS}

$\mathrm{ZnO}$ films doped with $\mathrm{Ni}$ were grown from $\mathrm{ZnO}: \mathrm{NiO}$ pellets with a mass ratio of $1: 1$, such pellets were used as a solid source which was obtained by compressing powders of ZnO (Mallinckrodt Chemical CAS 1314-13-2, St. Louis, MO, USA), and NiO (ALDRICH CAS 1313-99-1, St. Louis, MO, USA) at a pressure of $600 \mathrm{Kgf} / \mathrm{cm}$. For the deposited films of undoped $\mathrm{ZnO}$, the compressed powders of $\mathrm{ZnO}$ were used as solid sources. For deposits of the films, p-type silicon substrates of $1.5 \mathrm{~cm}^{2}$, with a resistivity of 5-10 $\Omega-\mathrm{cm}$ and $\langle 100\rangle$ oriented were used. Films of $\mathrm{ZnO}$ :Ni were grown by the HFCVD method. Such technique involves heating up to $2000{ }^{\circ} \mathrm{C}$ a tungsten filament. The substrate is exposed to a region where $\mathrm{H}_{2}$ species have higher kinetic energy because $\mathrm{H}_{2}$ is thermally activated in the filament. This configuration can lead to greater interaction between the growth of $\mathrm{ZnO}$ and the $\mathrm{H}_{2}$ species.

The following chemical reaction is proposed:

$M O(g)+H_{2}(g)=M(s)+H_{2} O(g)$ 
where $\mathrm{MO}$ is a Metal Oxide $(\mathrm{ZnO}$ or Nickel Oxide $(\mathrm{NiO}))$, $\mathrm{H}_{2}$ is molecular hydrogen, $\mathrm{M}$ is a Metal and, $\mathrm{H}_{2} \mathrm{O}$ water molecule [20]. According to equation (1), it was expected that both metal Nickel (Ni) and Zinc (Zn) with lower melting points (mp) (1455 and $420{ }^{\circ} \mathrm{C}$, respectively) than $\mathrm{NiO}$ and $\mathrm{ZnO}$ (1955 and $1974{ }^{\circ} \mathrm{C}$, respectively) can be easily sublimed. Into the gaseous phase and under an oxidant atmosphere, $\mathrm{NiO}$ and $\mathrm{ZnO}$ films are expected to be grown over the substrate. The distance between the filament and the source was calibrated to reach a temperature of 500 ${ }^{\circ} \mathrm{C}$ on the substrate surface. The growth process was carried out as a result of the reactivity of the atmosphere into the HFCVD reactor which increases and promotes the precursor gas formation. In the experiment, a flow of hydrogen gas at a constant rate of $50 \mathrm{sccm}$ through the filament for $60 \mathrm{~s}$ was used [21]. The hydrogen gaseous atmosphere used was of chromatographic grade supplied by INFRA. $\mathrm{H}_{2}$ reacted with a $\mathrm{ZnO}$ : $\mathrm{NiO}$ source generates gas precursors.

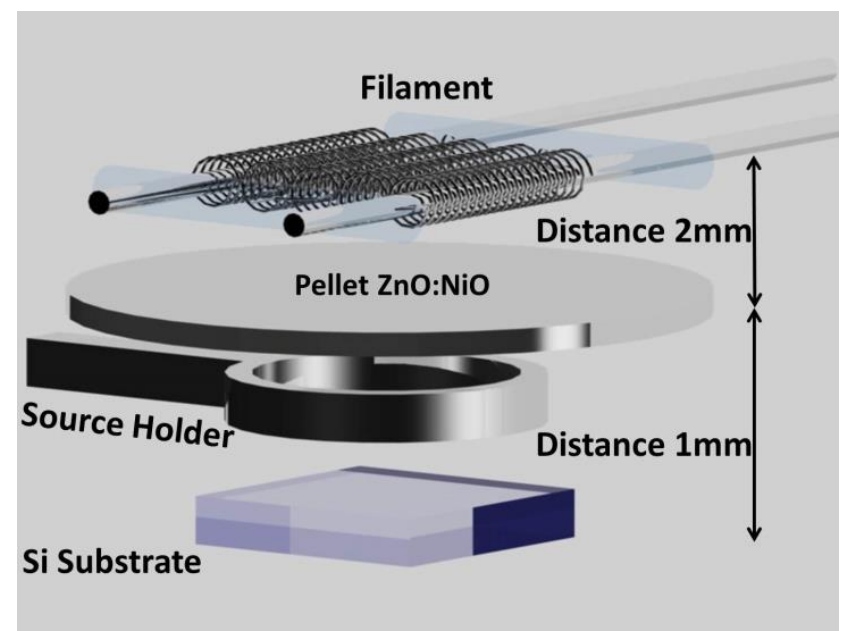

Fig. 1. The experimental arrangement at the center of the HFCVD system.

To study the effect of doping in $\mathrm{ZnO}$ with Nickel, experiments were performed under the same conditions using an undoped $\mathrm{ZnO}$ pellet. The $\mathrm{X}$-ray diffraction measurements were carried out on a Bruker AXS D8 Discovery (Billerica, MA, USA) diffractometer. Copper radiation with a wavelength of $1.54 \AA$, was used. PL spectra was obtained using a Fluoro max 3 system (HORIBA, Ltd., Kyoto, Japan), with an excitation wavelength of $330 \mathrm{~nm}$. Morphological characterization of the microstructures was made with an AURIGA 3916-FESEM scanning electron microscope (Zeiss, Jena, Germany).

TABLE I: EXPERIMENTAL DETAILS FOR THE GROWTH OF THE FILMS

\begin{tabular}{cccc}
\hline \hline Label & $\begin{array}{c}\text { The Weight } \\
\text { percentage ratio } \\
\text { of ZnO:NiO }\end{array}$ & $\begin{array}{c}\text { Substrate } \\
\text { temperature }\end{array}$ & $\begin{array}{c}\text { The time } \\
\text { process }\end{array}$ \\
\hline S0 & $1: 0$ & 500 & $1 \mathrm{~min}$ \\
S1 & $1: 1$ & 500 & $1 \mathrm{~min}$ \\
\hline \hline
\end{tabular}

\section{RESUlTS AND DISCUSSION}

\section{A. X-ray Diffraction Analysis}

Fig. 2 shows the diffractograms of the samples grown at $500{ }^{\circ} \mathrm{C}$. The diffraction peaks located at $2(\theta)=32^{\circ}, 34.6^{\circ}$, $47.8^{\circ}, 56.8^{\circ}, 63.1^{\circ}, 68^{\circ}$ and $69.3^{\circ}$ corresponding to the planes (100) (002) (101) (102) (110) (103) (112) and (201) of the hexagonal crystal structure of $\mathrm{ZnO}$ (ICDD \#00-036$1451)$, indicated by a vertical red line. The peaks located at $2(\theta)=36.4^{\circ}, 39.2^{\circ}, 43.3^{\circ}, 54.5^{\circ}$ and $70.8^{\circ}$ match to the planes (002), (100), (101), (102) and (110) corresponding to $\mathrm{Zn}$ in the hexagonal phase (ICDD \# 00-001-1244), indicated by a vertical green line.

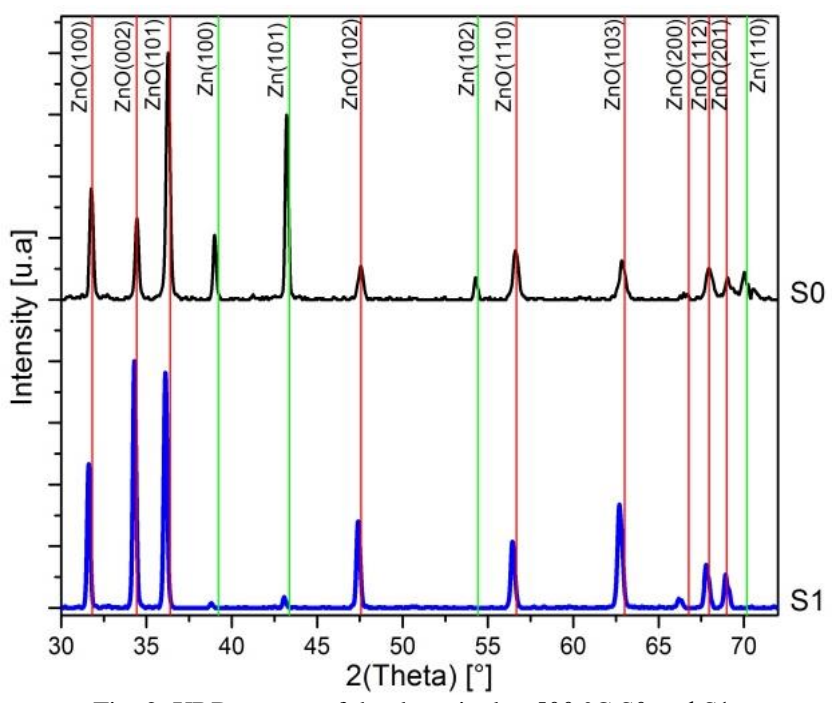

Fig. 2. XRD pattern of the deposited at $500^{\circ} \mathrm{C} \mathrm{S} 0$ and S1.

In XRD patterns from undoped $\mathrm{ZnO}$ film (labeled as S0) and $\mathrm{ZnO}: \mathrm{Ni}$ fils (labeled S1) the hexagonal phase of $\mathrm{ZnO}$ and $\mathrm{Zn}$ were observed. The analysis of the patterns showed a small shift to the left in the peaks of $\mathrm{ZnO}: \mathrm{Ni}$ with respect to the diffraction peaks of the $\mathrm{ZnO}$ film. The effect is probably caused by a compression-type micro-stress attributed to the $\mathrm{Ni}$ atoms, that substitute $\mathrm{Zn}$ atoms inside the $\mathrm{ZnO}$ structure [22] or to the fact that the ionic radius of $\mathrm{Ni}(0.68 \AA)$ is slightly bigger than the ionic radius of $\mathrm{Zn}(0.60 \AA)$ [23].

\section{B. Scanning Electron Microscopy (SEM)}

In the SEM micrograph of undoped $\mathrm{ZnO}$ film Fig. 3(a), microsphere morphology on the surface of this structure a chain-like framework is observed. In the same way, this growth is shown in the deep of the microstructure. In Fig. 3(b), of the sample of $\mathrm{ZnO}: \mathrm{Ni}$, the morphology of microsphere type is shown. On the surface of the microstructure, a nano-wires type structure can be seen over all the surfaces of the film. In both processes the growth mechanism for these microstructures is as follows, first, the $\mathrm{Zn}$ atoms are dispersed on the substrate surface which was heated at $500{ }^{\circ} \mathrm{C}$. The hot filament simultaneously heats the substrate and the source maintaining a temperature gradient between them, which facilitates the transport of the material The $\mathrm{Zn}$ powders $\mathrm{mp}=420{ }^{\circ} \mathrm{C}$ are the first to melt and aggregate to form droplets on the surface of the substrate. The decomposition of the surface is generated an atmosphere rich in oxygen inside the reaction chamber [24]. During the nucleation, the oxygen bound with $\mathrm{Zn}$ droplet forming $\mathrm{Zn}$ and $\mathrm{ZnO}$ Core-Shell. The difference between these processes consists of the function of the $\mathrm{Ni}$ atoms, that act as a catalyst, favoring the growth of $\mathrm{ZnO}$ nano-wire on the surface of the microsphere, forming shapes like a sea urchin [25] (see Fig 3(b)). 


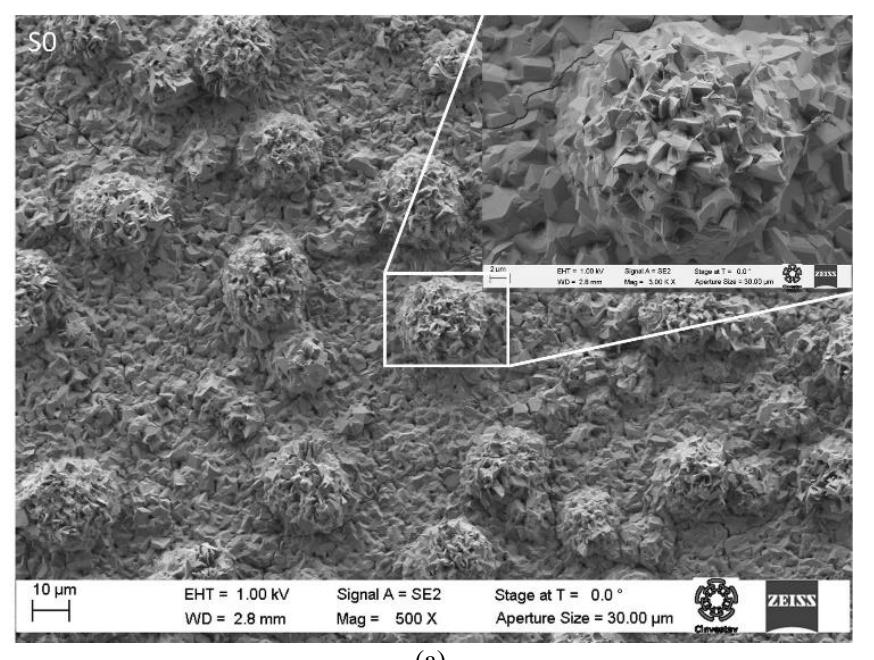

(a)

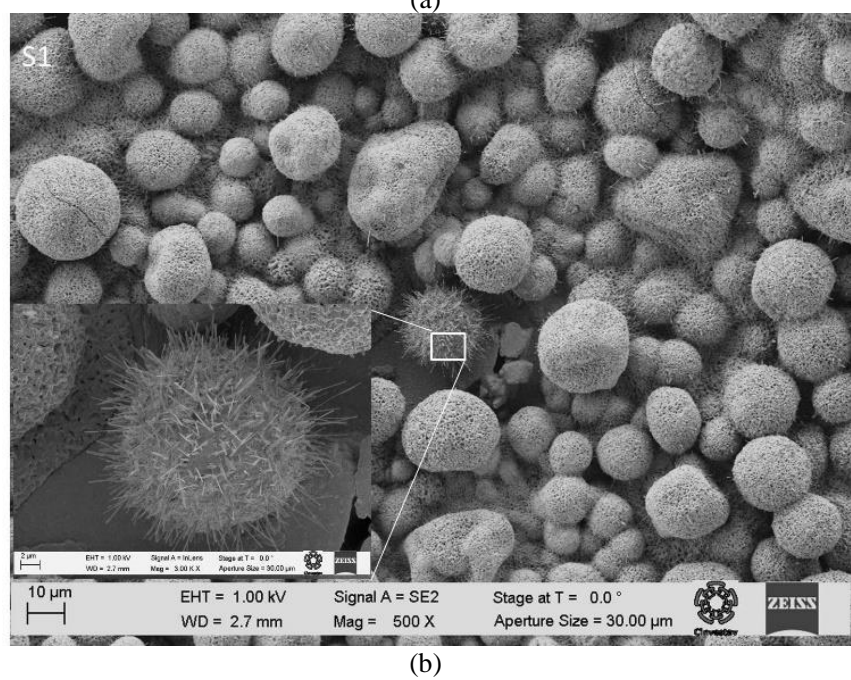

Fig. 3. SEM micrographs of the sample (a) S0, (b) S1.

\section{Energy Dispersive Spectroscopy (EDS)Analysis}

EDS spectrum has been determined for different regions of the S0 and S1 films, see Table II. According to the analysis of the results, for undoped $\mathrm{ZnO}$ (S0) film the amount of $\mathrm{Zn}$ is bigger than the $\mathrm{O}$. (on average 80 at\% and 20 at\%, respectively). The $\mathrm{ZnO}: \mathrm{Ni}$ (S1) film can see a decrease in $\mathrm{Zn}$ and an increase in $\mathrm{Ni}$ (on average 80 at\% and 0.3 at $\%$, respectively). EDS analysis was performed inside the microsphere, S0 and S1 films rich in Zn were observed, (on average 80 at\%). This ratifies the aforementioned.

TABLE II: The ATOMIC PERCENTAGE OF UndoPed ZNO AND ZNO:Ni FILMS OBTAINED BY HFCVD TECHNIQUE

\begin{tabular}{ccccc}
\hline \hline \multicolumn{5}{c}{ Atomic percentage of elements $(\%)$} \\
\hline \hline Label & $\mathrm{Zn}$ & $\mathrm{O}$ & $\mathrm{Ni}$ & Total \\
\hline S0 & 80.34 & 19.66 & - & 100 \\
S1 & 80.05 & 19.66 & 0.29 & 100 \\
\hline \hline
\end{tabular}

\section{Photoluminescence $(P L)$}

Fig. 4(a), are shown the PL-spectrum for the films of S0 and $\mathrm{S} 1$ at room temperature. The most notable effect of the incorporation of $\mathrm{Ni}$ in the $\mathrm{ZnO}$ matrix is the increase in the PL intensity emission band located at 410 and $700 \mathrm{~nm}$ (1.77 eV-3.02 eV). In addition, the maximum emission shifts to higher energy in S1. This could mean that there is an increase and/or introduction of $\mathrm{Ni}$ radiative centers in the $\mathrm{ZnO}$. In Fig. 4(b), the deconvolution of the spectrum S1 was performed in order to obtain the bands that compose such spectrum. It was observed that the maximum emission is centered in the energy range of the green emission band, around 509-520 nm (2.45-2.39 eV). This optical behavior of $\mathrm{ZnO}$ is usually associated with the presence of several types of defects as $\mathrm{V}_{\mathrm{O}}, \mathrm{V}_{\mathrm{Zn}}, \mathrm{Zn}_{\mathrm{i}}, \mathrm{O}_{\mathrm{i}}, \mathrm{O}_{\mathrm{Zn}}$ [26] or some metals transitions [24-26], generation recombination centers inside the bandgap $\left(\mathrm{E}_{\mathrm{g}}\right)$ of the structure.

Hwang et al.[29] and Fedorov et al.[5], associate the green emission band to undoped $\mathrm{ZnO}$ with the presence of $V_{O}$ and $V_{Z n}$ [27],[30] that introduces deep acceptors in the $\mathrm{E}_{\mathrm{g}}$. Green luminescence is because of the electronic transition between shallow donors and deep acceptors.

The material $\mathrm{Zn}$-rich guarantees the existence of $\mathrm{V}_{\mathrm{O}}$. The transition between those states and $\mathrm{V}_{\mathrm{O}}$ (deep acceptor states) might be the origin of the increase in the green emission band. Additionally, a blue luminescence band emerges around $450 \mathrm{~nm}(2.21 \mathrm{eV})$ in the $\mathrm{ZnO}$ PL spectrum. Recently Zeng et al. [31] and Cao et al.[32], obtained visible dichromatic photoluminescence emitting in blue/violet, and green regions, introducing $\mathrm{Zn}_{\mathrm{i}}$ defects in the $\mathrm{ZnO}$ structure.

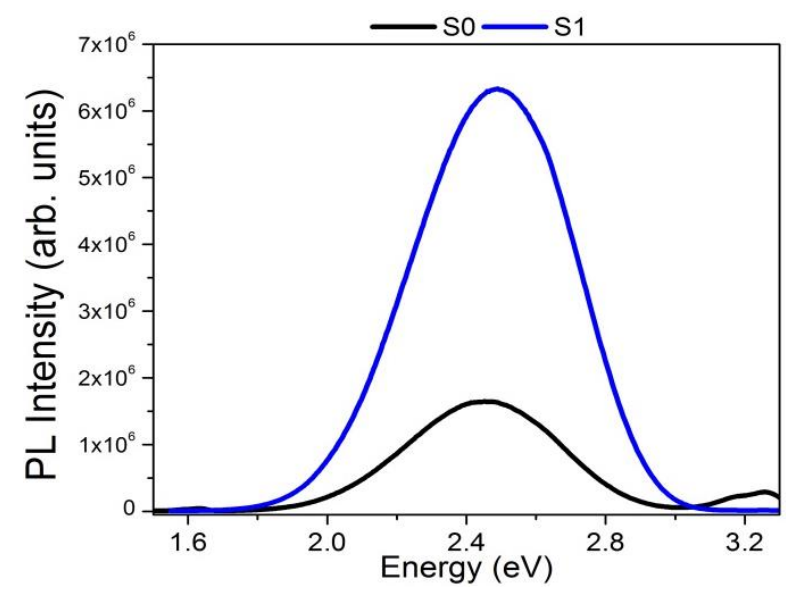

(a)

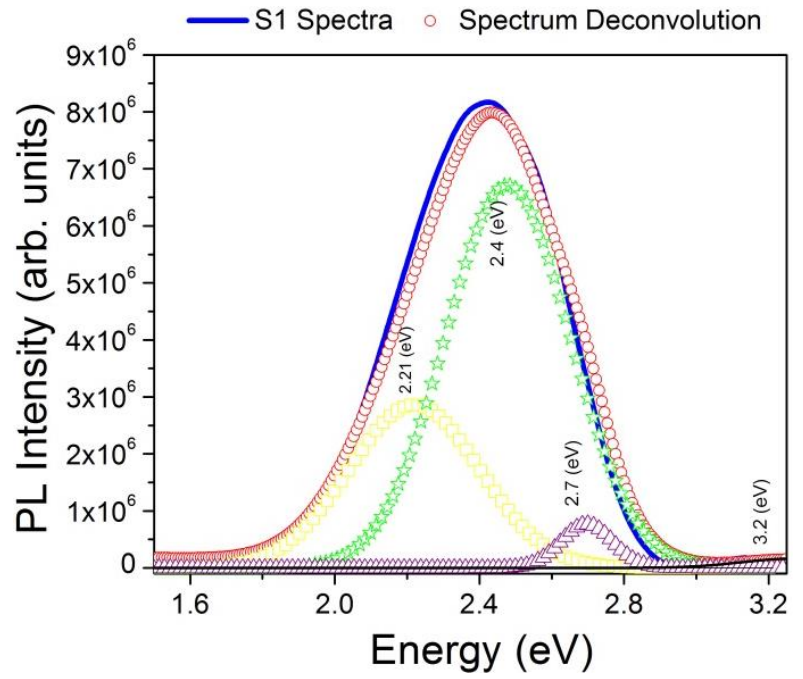

(b)

Fig. 4. Photoluminescence spectrum of (a) $\mathrm{ZnO}$ undoped and $\mathrm{ZnO}: \mathrm{Ni}$; Deconvolution spectrum on (b) $\mathrm{ZnO}$ :Ni sample.

\section{CONCLUSION}

$\mathrm{ZnO}$ and $\mathrm{ZnO}: \mathrm{Ni}$ films were grown using the HFCVD technique and pellets of $\mathrm{ZnO}$ and $\mathrm{ZnO}: \mathrm{NiO}$ as oxidant agents. Probably Ni atoms modify the crystalline structure 
of $\mathrm{ZnO}$ since it causes a shift in the position of the diffraction peaks with respect to undoped $\mathrm{ZnO}$. By SEM, shapes like a sea urchin due to the doping of $\mathrm{ZnO}$ were observed. The growth of these nanostructures resulted in a larger surface area, increasing the number of defects on the surface of the $\mathrm{ZnO}: \mathrm{Ni}$ film compared to the undoped $\mathrm{ZnO}$ structures. The green-yellow emission band is due to defects in $\mathrm{Zn}_{\mathrm{i}}, \mathrm{V}_{\mathrm{O}}, \mathrm{O}_{\mathrm{i}}, \mathrm{O}_{\mathrm{Zn}}$, and some $\mathrm{V}_{\mathrm{O}}$ complexes. This work shows the possibility of obtained $\mathrm{ZnO}: \mathrm{Ni}$ films in a short time process that implies a lower cost for the manufacturing of the optoelectronic device.

\section{ACKNOWLEDGMENT}

The authors acknowledge with gratitude the: Dr. M. Aceves to the Instituto Nacional de Astrofísica Óptica y Electrónica (INAOE) for the measurements of PL, and Dr. Jorge Roque to the Laboratorio Avanzado de Nanoscopía Electrónica (LANE-CINVESTAV) for help in the measurements of SEM-EDS.

\section{REFERENCES}

[1] Ü. Özgür et al., "A comprehensive review of $\mathrm{ZnO}$ materials and devices," J. Appl. Phys., vol. 98, no. 4, pp. 1-103, 2005.

[2] J. Wang, R. Chen, L. Xiang, and S. Komarneni, "Synthesis, properties and applications of $\mathrm{ZnO}$ nanomaterials with oxygen vacancies: A review," Ceram. Int., vol. 44, no. 7, pp. 7357-7377, 2018.

[3] L. Umaralikhan and M. J. M. Jaffar, "Green synthesis of $\mathrm{ZnO}$ and $\mathrm{Mg}$ doped $\mathrm{ZnO}$ nanoparticles, and its optical properties," J. Mater. Sci. Mater. Electron., vol. 28, no. 11, pp. 7677-7685, 2017.

[4] C. C. Singh and E. Panda, "Zinc interstitial threshold in Al-doped $\mathrm{ZnO}$ film: Effect on microstructure and optoelectronic properties," $J$. Appl. Phys., vol. 123, no. 16, 2018.

[5] A. S. Fedorov, M. A. Visotin, A. S. Kholtobina, A. A. Kuzubov, N. S. Mikhaleva, and H. S. Hsu, "Investigation of intrinsic defect magnetic properties in wurtzite $\mathrm{ZnO}$ materials," J. Magn. Magn. Mater., vol. 440, pp. 5-9, 2017.

[6] Y. R. Ryu, S. Zhu, D. C. Look, J. M. Wrobel, H. M. Jeong, and H. W. White, "Synthesis of p-type ZnO films," J. Cryst. Growth, vol. 216, no. 1, pp. 330-334, 2000 .

[7] K. H. Bang, D. K. Hwang, M. C. Park, Y. D. Ko, I. Yun, and J. M. Myoung, "Formation of p-type $\mathrm{ZnO}$ film on InP substrate by phosphor doping," Appl. Surf. Sci., vol. 210, no. 3-4, pp. 177-182, 2003.

[8] Y.-Z. Li, Q.-J. Feng, B. Shi, C. Gao, D.-Y. Wang, and H.-W. Liang, "Room temperature non-balanced electric bridge ethanol gas sensor based on a single $\mathrm{ZnO}$ microwire," Chinese Phys. B, vol. 29, no. 1, p. $18102,2020$.

[9] D. Alameri, L. E. Ocola, and I. Kuljanishvili, “ Mask-free fabrication and chemical vapor deposition synthesis of ultrathin zinc oxide microribbons on $\mathrm{Si} / \mathrm{SiO} 2$ and 2D substrates ," J. Vac. Sci. Technol. A, vol. 36, no. 5, p. 05G506, 2018.

[10] S. R. Christy, L. S. Priya, M. Durka, A. Dinesh, N. Babitha, and S. Arunadevi, "Simple Combustion Synthesis, Structural, Morphological, Optical and Catalytic Properties of $\mathrm{ZnO}$ Nanoparticles," J. Nanosci. Nanotechnol., vol. 19, no. 6, pp. 3564 $3570,2019$.

[11] N. P. Shetti, S. D. Bukkitgar, K. R. Reddy, C. V. Reddy, and T. M. Aminabhavi, "ZnO-based nanostructured electrodes for electrochemical sensors and biosensors in biomedical applications," Biosens. Bioelectron., vol. 141, no. March, p. 111417, 2019.

[12] W. A. Bhutto et al., "Controlled Growth of Zinc Oxide Nanowire Arrays by Chemical Vapor Deposition ( CVD ) Method," vol. 19, no. 8, pp. 135-141, 2019.

[13] L. Martínez, D. Becerra, and V. Agarwal, "Dual layer $\mathrm{ZnO}$ configuration over nanostructured porous silicon substrate for enhanced memristive switching," Superlattices Microstruct., vol. 100, pp. 89-96, 2016.

[14] M. Willander, M. A. Abbasi, K. Khun, M. Hussain, Z. H. Ibupoto, and O. Nur, "UV detectors and LEDs in different metal oxide nanostructures," Oxide-based Mater. Devices V, vol. 8987, p.
89871Y, 2014.

[15] Y. Ning, Z. Zhang, F. Teng, and X. Fang, "Novel Transparent and Self-Powered UV Photodetector Based on Crossed ZnO Nanofiber Array Homojunction," Small, vol. 14, no. 13, pp. 1-9, 2018.

[16] F. Khan, W. Khan, and S. D. Kim, "High-performance ultraviolet light detection using nano-scale-fin isolation $\mathrm{AlGaN} / \mathrm{GaN}$ heterostructures with $\mathrm{ZnO}$ nanorods," Nanomaterials, vol. 9, no. 3, pp. 1-14, 2019.

[17] S. H. Park, "Properties of the Two-Dimensional Electron-Gas of a Hybrid $\mathrm{MgZnO} / \mathrm{InGaN} / \mathrm{ZnO}$ Heterostructure with an InGaN Channel Layer," J. Korean Phys. Soc., vol. 75, no. 4, pp. 326-330, 2019.

[18] K. Ding, V. Avrutin, N. Izyumskaya, Ü. Özgür, and H. Morkoç, "Comparative study of $\mathrm{BeMgZnO} / \mathrm{ZnO}$ heterostructures on c-sapphire and GaN by molecular beam epitaxy," J. Vac. Sci. Technol. A Vacuum, Surfaces, Film., vol. 38, no. 2, p. 23408, 2020.

[19] Y.-H. Yang, J. Li, Q. Chen, W.-Q. Zhu, X.-F. Li, and J.-H. Zhang, "Graphitic carbon nitride/polyvinylpyrrolidone composite dielectric for low-voltage flexible InZnO thin film transistor grown on a polyethylene terephthalate substrate," IEEE Electron Device Lett. vol. 41, no. 3, pp. 381-384, 2020.

[20] H. G. Lintz, "Transition Metal Oxides: Surface Chemistry and Catalysis," 1990, pp. 895-895.

[21] R. López, G. García, A. Coyopol, T. Díaz, and E. Rosendo, "Effect of nitrogen gas in the agglomeration and photoluminescence of $\mathrm{Zn}-\mathrm{ZnO}$ nanowires after high-temperature annealing," Rev. Mex. fisica, vol. 62 , no. 1, pp. 1-4, 2016

[22] B. D. Cullity and S. R. Stock, "Elements of X-ray Diffraction, Third Edition ." Prentice-Hall , New York, 2001.

[23] R. Elilarassi and G. Chandrasekaran, "Synthesis , Structural and Magnetic Characterization of Ni-Doped $\mathrm{ZnO}$ Diluted Magnetic Semiconductor," Am. J. Mater. Sci., vol. 2, no. 3, pp. 46-50, 2012.

[24] Q. Ahsanulhaq, J. H. Kim, N. K. Reddy, and Y. B. Hahn, "Growth mechanism and characterization of rose-like microspheres and hexagonal microdisks of $\mathrm{ZnO}$ grown by surfactant-free solution method," J. Ind. Eng. Chem., vol. 14, no. 5, pp. 578-583, 2008.

[25] S. H. Kim, A. Umar, and Y.-B. Hahn, "Growth and formation mechanism of sea-urchin like $\mathrm{ZnO}$ nanostructures on Si," Korean J. Chem. Eng., vol. 23, no. 6, pp. 1069-1069, 2006.

[26] H.-M. Xiong, D. G. Shchukin, H. Möhwald, Y. Xu, and Y.-Y. Xia, "Sonochemical Synthesis of Highly Luminescent Zinc Oxide Nanoparticles Doped with Magnesium(II)," Angew. Chemie Int. Ed., vol. 48, no. 15, pp. 2727-2731, 2009

[27] R. Janisch, P. Gopal, and N. A. Spaldin, "Transition metal-doped $\mathrm{TiO} 2$ and $\mathrm{ZnO}$ - Present status of the field," J. Phys. Condens. Matter, vol. 17 , no. 27,2005

[28] B. Lin, Z. Fu, and Y. Jia, "Green luminescent center in undoped zinc oxide films deposited on silicon substrates," Appl. Phys. Lett., vol. 79, no. 7, pp. 943-945, 2001.

[29] D. K. Hwang et al., "Study of the photoluminescence of phosphorusdoped $\mathrm{p}$-type $\mathrm{ZnO}$ thin films grown by radio-frequency magnetron sputtering," Appl. Phys. Lett., vol. 86, no. 15, pp. 1-3, 2005.

[30] F. H. Leiter, H. R. Alves, A. Hofstaetter, D. M. Hofmann, and B. K Meyer, "The oxygen vacancy as the origin of a green emission in undoped ZnO," Phys. Status Solidi Basic Res., vol. 226, no. 1, pp. 5$6,2001$.

[31] H. Zeng, W. Cai, J. Hu, G. Duan, P. Liu, and Y. Li, "Violet photoluminescence from shell layer of $\mathrm{Zn} / \mathrm{ZnO}$ core-shell nanoparticles induced by laser ablation," Appl. Phys. Lett., vol. 88, no. 17, pp. 1-4, 2006

[32] B. Cao, W. Cai, and H. Zeng, "Temperature-dependent shifts of three emission bands for $\mathrm{ZnO}$ nanoneedle arrays," Appl. Phys. Lett., vol 88 , no. 161101 , pp. 1-4, 2006. 